\title{
Unraveling the differential functions and regulation of striatal neuron sub-populations in motor control, reward, and motivational processes
}

\author{
Sabrina Ena, Alban de Kerchove d'Exaerde and Serge N. Schiffmann*
}

Laboratory of Neurophysiology, School of Medicine, Université Libre de Bruxelles, Brussels, Belgium

Edited by:

Gilberto Fisone, Karolinska Institutet, Sweden

\section{Reviewed by:}

Gilberto Fisone, Karolinska Institutet, Sweden

Denis Hervé, Institut du Fer-à-Moulin, France

\section{*Correspondence:}

Serge N. Schiffmann, Laboratory of Neurophysiology, Université Libre de Bruxelles, Campus Erasme CP 601, 808, Route de Lennik, B-1070 Brussels, Belgium.

e-mail:sschiffm@ulb.ac.be
The striatum, the major input structure of the basal ganglia, is critically involved in motor control and learning of habits and skills, and is also involved in motivational and reward processes. The dorsal striatum, caudate-putamen, is primarily implicated in motor functions whereas the ventral striatum, the nucleus accumbens, is essential for motivation and drug reinforcement. Severe basal ganglia dysfunction occurs in movement disorders as Parkinson's and Huntington's disease, and in psychiatric disorders such as schizophrenia and drug addiction. The striatum is essentially composed of GABAergic medium-sized spiny neurons (MSNs) that are output neurons giving rise to the so-called direct and indirect pathways and are targets of the cerebral cortex and mesencephalic dopaminergic neurons. Although the involvement of striatal sub-areas in motor control and motivation has been thoroughly characterized, major issues remained concerning the specific and respective functions of the two MSNs sub-populations, $\mathrm{D}_{2} \mathrm{R}$-striatopallidal (dopamine $\mathrm{D}_{2}$ receptor-positive) and $\mathrm{D}_{1} \mathrm{R}$-striatonigral (dopamine $\mathrm{D}_{1}$ receptor-positive) neurons, as well as their specific regulation. Here, we review recent advances that gave new insight in the understanding of the differential roles of striatopallidal and striatonigral neurons in the basal ganglia circuit. We discuss innovative techniques developed in the last decade which allowed a much precise evaluation of molecular pathways implicated in motivational processes and functional roles of striatopallidal and striatonigral neurons in motor control and in the establishment of reward-associated behavior.

Keywords: striatum, medium-sized spiny neurons, transgenic mouse model

\section{INTRODUCTION}

The basal ganglia are composed of several interconnected nuclei involved in adaptive control of motor, cognitive, and motivational behavior. Dysfunctions of the basal ganglia system occur in several neuro-psychiatric diseases as Parkinson's (PD) and Huntington's diseases, addiction, attention deficit hyperactivity disorder (ADHD), schizophrenia, and Tourette's syndrome (Delong, 1990; Comings, 2001; Saka and Graybiel, 2003; Chao and Nestler, 2004; Graybiel, 2005; Delong and Wichmann, 2007; Keshavan et al., 2008). The striatum, the main input structure of this system, is subdivided in a dorsal part mainly involved in motor control (Graybiel et al., 1994; Hikosaka et al., 2000; Packard and Knowlton, 2002; Yin and Knowlton, 2006; Nicola, 2007) and the ventral striatum or nucleus accumbens (NAc) which is implicated in motivational and reward processes (Belin et al., 2009). In rodents, the striatum is composed of about $95 \%$ of GABAergic projection medium-sized spiny neurons (MSNs) and $5 \%$ of interneurons, including three subtypes of GABAergic neurons and the large aspiny cholinergic neurons (Kawaguchi et al., 1995; Bolam et al., 2000; Tepper and Bolam, 2004). MSNs can be subdivided in two neuronal sub-populations according to their projection sites and their expression in receptors and neuropeptides (Graybiel, 2000). Striatonigral neurons, giving rise to the direct pathway, project monosynaptically to the substantia nigra pars reticulata ( $\mathrm{SNr}$ ) and the medial globus pallidus (MGP), the output structures of basal ganglia. They are enriched in the neuropeptides substance $\mathrm{P}(\mathrm{Tac} 1)$ and dynorphin $(P d y n)$ and in dopamine $\mathrm{D}_{1}$ receptor $\left(\mathrm{D}_{1} \mathrm{R} ; \operatorname{Drd1a}\right)$ and $\mathrm{M} 4$ muscarinic acetylcholine receptor (Chmr4; Gerfen and Young, 1988; Gerfen et al., 1990; Le Moine et al., 1991; Bernard et al., 1992; Ince et al., 1997). Striatopallidal neurons participate to the indirect pathway and project to the lateral globus pallidus (LGP). This indirect pathway reaches the SNr/MGP by synaptic relay through the subthalamic nucleus (STN). Striatopallidal neurons specifically express the neuropeptide enkephalin (Penk1) and dopamine $\mathrm{D}_{2}$ receptor $\left(\mathrm{D}_{2} \mathrm{R} ; \operatorname{Drd} 2\right)$ and adenosine $\mathrm{A}_{2 \mathrm{~A}}$ receptor $\left(\mathrm{A}_{2 \mathrm{~A}} \mathrm{R} ;\right.$ Adora $2 a$; Gerfen and Young, 1988; Gerfen et al., 1990; Schiffmann et al., 1991, 2007).

In the 90s, Albin et al. (1989) propose a model of the basal ganglia in which the direct and indirect pathways would have an opposite but balancing role in the control of the motor behavior. In this model, the striatonigral direct pathway would promote the movement whereas the striatopallidal indirect pathway would inhibit the motor behavior (Albin et al., 1989; Delong and Wichmann, 2007). MSNs are also involved in reward and motivational processes (addiction) but their differential function in the establishment of such behavior are still poorly understood.

The two MSN populations are morphologically very similar and heterogeneously distributed in the striatum making difficult a specific identification and analysis. These characteristics preclude a satisfactory demonstration of their differential functions in the motor and reward behavior for decades. The recent emergence of new 
methodologies as BAC transgenesis, optogenetic, viral transgenesis allowing to target these neurons has given the opportunity to override this problem leading to a more specific investigation of striatopallidal and striatonigral neuron functions in the basal ganglia circuit. Here, we review the most recent advances regarding the differential role of striatopallidal and striatonigral neurons in the basal ganglia system. We will describe the innovative techniques used to investigate the gene expression profiles and the molecular pathways involved in the response to multiple stimuli (i.e., psychostimulants, 6-OHDA-induced dopamine depletion L-DOPA) in the two MSN sub-populations. We will also discuss the important contribution of cell-specific ablation models and conditional knock-out models to unravel the functional roles of these striatopallidal and striatonigral neurons in the motor and motivational behavior.

\section{BAC TRANSGENIC REPORTER MICE AND EVALUATION OF MOLECULAR SIGNALING IN STRIATOPALLIDAL AND STRIATONIGRAL NEURONS}

The recent development of transgenic BAC reporter mouse lines in which the enhanced green fluorescent protein (EGFP) gene is selectively expressed in a large variety of neuronal sub-populations represents a powerful tool for identifying each neuronal subtype in different experimental paradigms. More particularly, BAC EGFP transgenic mice allowed to specifically identify and study the differential functional in vivo signaling of the two distinct MSN neuronal populations. In these transgenic mice, EGFP or dtTomato (a red fluorescent protein) are expressed under the control of Drd1a or Drd2 promoter in order to target the striatonigral (Drd1a-EGFP and Drd1a-dtTomato) and striatopallidal neurons (Drd2-EGFP), respectively (Gong et al., 2003; Shuen et al., 2008). The detailed study of the different mouse lines matched and confirmed previous in situ hybridization or immunohistochemical studies (Gerfen and Young, 1988; Le Moine et al., 1991; Schiffmann et al., 1991; Levesque et al., 2003) that led to the two-pathways model of basal ganglia. The Drd1a-EGFP and Drd1a-dtTomato mice, as well as A Chrm4-EGFP line, allowed the identification of striatonigral neurons and their projection structures (MGD and $\mathrm{SNr}$ ) whereas the Drd2-EGFP labeled striatopallidal neurons and their projection area (LGP) but also the cholinergic interneurons as well as neurons in the substantia nigra pars compacta and ventral tegmental area corresponding to neurons expressing $\mathrm{D}_{2} \mathrm{R}$ as an autoreceptor (Gong et al., 2003; Bertran-Gonzalez et al., 2008; Shuen et al., 2008; Matamales et al., 2009). Thus, these mice are valid tools to specifically identify the two MSN populations and allowed to investigate and compare molecular pathways and molecular changes taking place in striatopallidal and striatonigral neurons in response to different stimuli (Bertran-Gonzalez et al., 2008, 2009; Borgkvist et al., 2008; Santini et al., 2009).

The extracellular signal regulated kinase (ERK) cascade is an important signaling pathway that underlies synaptic plasticity, cellular excitability and learning. ERK is activated in the striatum by coordinated dopamine and glutamate receptor signaling, where it underlies corticostriatal synaptic plasticity and influences striatal cell excitability. ERK activation is necessary for action-outcome learning and performance of goal-directed actions (Shiflett and Balleine, 2010). The activation of the ERK pathway distinctly in the two MSN populations has been implicated in the long lasting effect of drugs of abuse (Valjent et al., 2006; Girault et al., 2007). Bertran-Gonzalez et al. (2008) demonstrated by immunofluorescence on Drd2-EGFP and Drd1a-EGFP mice that the ERK pathway activation occurs specifically in striatonigral neurons after acute and even repeated cocaine administration. Moreover, this activation is concomitant to the phosphorylation of MSK1, an important player in the phosphorylation of CREB and histone $\mathrm{H} 3$ in the striatum in response to cocaine (Bertran-Gonzalez et al., 2008). This ERK pathway is also functional in striatopallidal neurons. The antipsychotic drug haloperidol known to antagonize $\mathrm{D}_{2} \mathrm{R}$ (Farde et al., 1988 ) induced an activation of ERK, MSK1, and histone H3 exclusively in striatopallidal neurons, showing the complete segregation between the striatopallidal and striatonigral signaling pathways within the striatum in response to diverse pharmacological stimuli (Bertran-Gonzalez et al., 2009). In contrast to striatonigral neurons, in striatopallidal neurons the $\mathrm{H} 3$ phosphorylation is occurring in an ERK-MSK1-independent manner (Bertran-Gonzalez et al., 2009). $\mathrm{H} 3$ phosphorylation involves the activation of the $\mathrm{A}_{2 \mathrm{~A}} \mathrm{R}$-Golf signaling cascade leading to the DARPP-32 phosphorylation and the inhibition of PP-1. Thus, the pathways involved in the phosphorylation of the histone $\mathrm{H} 3$, reflecting the chromatin remodeling, are clearly different in striatopallidal and striatonigral neurons. Santini et al. (2009) have demonstrated that the same molecular mechanism observed in response to drug of abuse in striatonigral neurons could be implicated in L-DOPA-induced dyskinesia. Single injection of L-DOPA in a 6-OHDA mouse model induced ERK activation in association with an increase of MSK1 and histone H3 phosphorylation. Moreover, chronic administration of $\mathrm{L}-\mathrm{DOPA}$ produced a persistent increase of ERK, phospho-MSK1 and phospho-H3 only in dyskinetic but not in non-dyskinetic mice and this increase is restricted to striatonigral neurons (Santini et al., 2009). Therefore, this increase in phosphorylated $\mathrm{H} 3$ could be associated with gene expression changes in striatonigral neurons that might play a role in the development of L-DOPA-induced dyskinesia.

Dopamine and cAMP-regulated phosphoprotein of $32 \mathrm{kDa}$ (DARPP-32) is a protein phosphatase inhibitor highly expressed in striatal MSNs (Walaas et al., 1983). DARPP-32 is a key regulator of protein phosphatase (PP-1) and protein kinase (PKA) signaling. DARPP-32 can be phosphorylated on different threonine residues that modify its activation state and induce opposite biochemical effects (inhibition of protein phosphatase or protein kinase; Fisone et al., 2007). Therefore, by acting on the phosphorylation state of multiple downstream targets, DARPP-32 is an important actor in striatal neurons; in control of their electrophysiological behavior and their implication in behavioral responses as reward, motor learning, and L-DOPA-induced dyskinesia (Valjent et al., 2005; Fisone et al., 2007; Santini et al., 2009; Bateup et al., 2010). Considering this central role, the respective involvement of DARPP32 in striatopallidal and striatonigral neurons functions was extensively studied. By using BAC transgenic mice expressing a tagged DARPP-32 specifically in striatopallidal or striatonigral neurons, Bateup et al. (2008) showed that the activation of $\mathrm{D}_{1} \mathrm{R}$ or $\mathrm{D}_{2} \mathrm{R}$ results in an opposite pattern of DARPP-32 phosphorylation. $\mathrm{D}_{1} \mathrm{R}$ activation leads to an increase of T34 phosphorylation and a decrease of T75 phosphorylation whereas $\mathrm{D}_{2} \mathrm{R}$ activation leads to the opposite effect. Moreover, different subclasses of psychostimulant and antipsychotic drugs are able to induce cell-specific pattern of 
DARPP-32 phosphorylation. Whereas cocaine induces specific T34 phosphorylation in striatonigral neurons, haloperidol treatment induces the same phosphorylation exclusively in striatopallidal neurons (Bateup et al., 2008). Moreover, Stipanovich et al. (2008) have shown using Drdla-EGFP mice that psychostimulant injection lead to the nuclear accumulation of phospho-T34-DARPP-32 in striatonigral neurons. They demonstrated that $\mathrm{D}_{1} \mathrm{R}$ activation leads to the phosphorylation of DARPP-32 on serine 97 that is responsible for the nuclear export and accumulation of DARPP32. This accumulation is also required for the phosphorylation of histone $\mathrm{H} 3$ and then is essential for regulation of gene expression. The knock-in mouse model bearing a point mutation of the serine 97 in alanine (S97A) showed that 997 mutation, and hence disruption of DARPP-32 nuclear accumulation, produced alteration in the long lasting effect of drug of abuse, and decreased motivation for food reward (Stipanovich et al., 2008). Meurers et al. (2009) have also recently shown in a striatopallidal and striatonigral neurons profile analysis that DARPP-32 pathway seems to be the target of adaptive modification in the two MSN populations in response to dopamine depletion and L-DOPA treatment.

Besides differences in signaling pathways, the study on Drd1aand Drd2-EGFP mouse lines also allowed to firmly demonstrate in striatopallidal and striatonigral neurons specific synaptic adaptations and plasticity such as structural changes associated to different conditions like induction of addictive behavior or motor deficits in PD. It is first worth to note that these mouse lines allowed to identify subtle morphological differences between $\mathrm{D}_{1}$ - and $\mathrm{D}_{2}-\mathrm{GFP}$ neurons with higher total dendritic length and higher number of primary dendrites in striatonigral than in striatopallidal neurons (Gertler et al., 2008).

Lee et al. (2006) have demonstrated an increase in spine density both in striatonigral and striatopallidal neurons after chronic methylphenidate and cocaine treatments. However, this increase persisted in striatonigral neurons after 1 month withdrawal whereas it rapidly disappeared in striatopallidal neurons similarly to the increase in $\Delta$ FosB expression (Lee et al., 2006), suggesting that the increase of dopaminergic tonus is responsible for the increase of spine density in both MSN sub-populations but with highly different long-term consequences.

On the other hand, Day et al. (2006) demonstrated that 6-OHDA-induced dopamine depletion provoked a selective loss of glutamatergic synapses in striatopallidal neurons, without any spine density modifications in striatonigral neurons, by a mechanism resulting from the dysregulation of the l-type $\mathrm{Ca}^{2+}$ channel Cav1.3 in the spine. Such dendritic spine density modification should alter striatopallidal MSN activity and lead to a failure in the correct control of the pallido-subthalamic circuit that could explain motor dysfunction observed in PD. This decrease could be viewed as a homeostatic plasticity to adapt to the decrease in $\mathrm{D}_{2} \mathrm{R}$ activation on striatopallidal neurons. This homeostatic hypothesis is also validated by the coincidence in these MSNs of an increased intrinsic excitability and a large decrease in their excitatory synaptic inputs resulting from the loss in dendritic spines in dopamine depletion condition (Azdad et al., 2009a).

Allowing to better understand the homeostatic control of spine density in striatopallidal neurons, Tian et al. (2010) demonstrated that sustained depolarization of co-culture of cerebral cortex and
$\mathrm{D}_{2}$-EGFP striatum induced about $50 \%$ loss of dendritic spines and glutamatergic synapses specifically in striatopallidal neurons as seen in the PD animal model (Day et al., 2006). This loss was dependent on Cav1.2, but not on Cav1.3 as in PD model (Day et al., 2006), on activation of calcineurin and up-regulation of one of its target Mef2 which is highly expressed in striatopallidal neurons. This increase induces an up-regulation of two genes, Nur77 and Arc, known to be involved in down-regulation of glutamatergic synapses and inhibition of synapse formation and dendritic spine differentiation (Steward and Worley, 2001; Shalizi et al., 2006; Shepherd et al., 2006). These results therefore identified new mechanisms of activity-dependent synaptic scaling specifically in striatopallidal MSN.

\section{SPECIFIC STRIATOPALLIDAL AND STRIATONIGRAL NEURONS TRANSCRIPTIONAL PROFILES}

Genome-wide transcriptional analysis has also recently emerged as a powerful tool to investigate the differential gene expression and gene function of defined cell types.

Recent studies have identified new molecular targets specific to either striatopallidal or striatonigral neurons (Lobo et al., 2006; Heiman et al., 2008). The molecular profiling is an important key to unravel the molecular differences between the two MSN populations in order to better understand their differential functions in the basal ganglia system. By FACS-array profiling of $\mathrm{D}_{1}$-EGFP and $D_{2}$-EGFP neurons, Lobo et al. (2006) identified a subset of new striatopallidal and striatonigral neuron-enriched genes. They have demonstrated the important role of Ebf1 selectively enriched in striatonigral neurons as regulator of the striatonigral neuron differentiation in the striatal matrix compartment (Lobo et al., 2008). Moreover, they identified a new striatal-specific constitutive G protein-coupled receptor (GPCR), GPR6, which is selectively expressed in striatopallidal neurons. Analysis of GPR6 KO mice demonstrated that this sphingosine-1-phosphate receptor is a critical factor in the striatal production of cAMP. GPR6 KO mice exhibited deficits in instrumental conditioning by which animal learn to obtain a reward by performing a simple task, whereas the locomotor behavior and the motor learning in a rotarod task were normal (Lobo et al., 2007). Therefore, GPR6 seems to be an important and new actor in molecular mechanisms underlying instrumental conditioning and points out the role of striatopallidal neurons in mediating this behavior.

Since gene profiling is therefore a powerful methodology to investigate the differences at the molecular level in striatopallidal and striatonigral neurons and to identify key genes or molecular pathways involved in the basal ganglia physiology, it should also provide new mechanistic data in models of pathological conditions of the basal ganglia circuit as in addiction or PD. Heiman et al. (2008) developed a TRAP (translating ribosome affinity purification) approach consisting in the generation of BAC transgenic mice expressing the EGFP-tagged ribosomal protein L10a specifically in striatopallidal and striatonigral neurons via the Drd2 and Drd1a gene promoters, respectively. After an affinity purification of the EGFP-L10a protein with an antibody against EGFP, the enriched ribosome and the associated mRNA were used to determine the translational profiles of both MSN populations (Heiman et al., 2008). This led to the confirmation of the Lobo's study and the identification of many new genes enriched in either striatopalli- 
dal or striatonigral neurons. This subset of genes has been also validated in adult mice by our group using FACS-array profiling of EGFP striatopallidal neurons targeted with the Adora2a-Cre mice (Durieux et al., 2009) and striatonigral neurons simultaneously identified by retrograde labeling (Ena et al., unpublished data).

Heiman et al. (2008) approach was also used to track for differential modifications in gene expression profiles in response to pharmacological perturbations. For instance, besides the identification of various genes whose expression has been previously reported to be affected, an up-regulation of the GABA signaling pathway was specifically demonstrated in striatonigral neurons upon chronic cocaine treatment (Heiman et al., 2008). Accordingly, electrophysiological recordings showed specific increase in MIPSC in striatonigral neurons (Heiman et al., 2008). Increased expression in $\mathrm{GABA}_{\mathrm{A}}$ receptor in striatonigral neurons could be part of molecular adaptive changes to the increased excitatory drive on these neurons and, hence, could be associated with the modification in sensitivity observed in chronic cocaine addicts. In contrast to this hyperdopaminergic situation upon psychostimulant treatment, Meurers et al. (2009) have recently shown that the expression of multiple components and targets of the CAMP/DARPP-32 signaling pathway are affected in mouse model of PD (6-OHDA mouse model) and after chronic L-DOPA treatment leading to L-DOPA-induced dyskinesia. By using an experimental approach based on a microarray analysis of laser-dissected striatopallidal and striatonigral neurons, these authors identified several gene categories (ion channels, receptors, signaling molecules) affected by the dopamine depletion. These genes were either altered exclusively in one population or in an opposite manner in the striatopallidal and striatonigral neurons. Moreover, Meurers and colleagues highlighted a cell-specific regulation of gene expression in response to chronic L-DOPA treatment, which could give new insight about the mechanism involved in the development of this condition.

\section{EVALUATION OF THE DIFFERENTIAL ROLES OF STRIATOPALLIDAL AND STRIATONIGRAL NEURONS IN MOTOR AND REWARD BEHAVIORS BY CELL-TYPE SPECIFIC ACTIVATION OR ABLATION}

According to the classical model of the basal ganglia, the two neuronal MSN populations exert opposite control on motor behavior. Activation of the "direct" pathway would lead to the facilitation of movements whereas the activation of the "indirect" pathway should inhibit the movement. However, the hypothesis was not experimentally validated because of the lack of tools allowing the specific study of these two morphological and intermixed neuronal populations in vivo. In the last 2 years, several groups have developed such tools allowing the analysis of functional differences between striatopallidal and striatonigral neurons in motor and reward behaviors. Durieux et al. (2009) have generated a conditional striatopallidal neuron ablation model based on an Adora2a-Cre BAC transgenic mouse. The specific ablation was obtained by stereotaxic injection of diphtheria toxin (DT) in the Adora2a-Cre mouse crossed with an inducible diphtheria toxin receptor (iDTR) mouse line (Buch et al., 2005). The bilateral injection of DT in the striatum induces a spontaneous hyperlocomotion compared to the control mice, definitively demonstrating the inhibitory role of striatopallidal neurons in the motor activity. Kravitz et al. (2010) recently confirmed this result by using optogenetic control of the two MSN populations. In this approach, adenovirus-associated viruses (AAV1) containing the channel rhodopsin 2 (Chr2) fused to enhanced yellow fluorescent protein (YFP) were injected into the dorsal striatum of BAC transgenic mice expressing the Cre recombinase in striatopallidal or striatonigral neurons (Kravitz et al., 2010; $\mathrm{D}_{2}$-Cre and $\mathrm{D}_{1}$-Cre respectively Gong et al., 2007). In $\mathrm{D}_{2}$-Chr2 mice, illumination of the dorsal striatum induced an activation of striatopallidal neurons leading to a decrease in locomotor initiation and an increase of freezing. In contrast, the activation of striatonigral neurons in $\mathrm{D}_{1}$-Chr2 mice led to the opposite phenotype, with an increase in locomotor initiation and decrease in freezing (Kravitz et al., 2010). Moreover, bilateral illumination of dopamine-depleted striatum in $\mathrm{D}_{1}$-Chr2 mice completely restored a normal motor behavior by eliminating bradykinesia, increasing the locomotor initiation, and decreasing freezing; firmly demonstrating the role of the activation of the direct pathway for improvement of motor deficits in PD (Kravitz et al., 2010).

The respective roles of striatopallidal and striatonigral neurons in the control of motivational and reward behavior are so far also poorly understood. However, thanks to the development of conditional tools, several recent studies have successfully addressed this issue. Durieux et al. (2009) have demonstrated that the conditional and specific ablation of striatopallidal neurons in the NAc induced an increase in drug reinforcement as demonstrated by an increased amphetamine conditioned place preference (CPP), strongly suggesting the role of striatopallidal neurons in inhibition of drug reinforcement.

Ferguson et al. (2010) have more recently developed a new system in rat based on the use of viral vector with Enkephalin (Penk) or Dynorphyn $(P d y n)$ gene promoters allowing the expression of the new engineered GPCR hMD4 specifically in striatopallidal or striatonigral neurons, respectively. The stimulation of hMD4, a $\mathrm{G}_{\mathrm{i} / \mathrm{o}}$ coupled GPCR, by a specific ligand CNO induces the activation of Kir3 resulting in a membrane hyperpolarization and, hence, a transient neuronal silencing. In this model, administration of CNO in Penk-hMD4 or Pdyn-hMD4 rats resulted in an increase and a decrease of amphetamine-induced sensitization, respectively (Ferguson et al., 2010). Lobo et al. (2010) have also addressed this question by using optogenetic control of striatopallidal and striatonigral neurons but also by generating conditional loss of TrkB in striatopallidal and striatonigral neurons using $\mathrm{D}_{2}$-Cre ad $\mathrm{D}_{1}$-Cre transgenic mice. They demonstrated that the activation of the indirect pathway in a CPP paradigm led to a decrease of the rewarding effect of cocaine whereas the activation of the direct pathway resulted in the opposite phenotype (Lobo et al., 2010). Finally, Hikida et al. (2010) have also targeted striatonigral and striatopallidal neurons by using viral vectors and Tacl or Penk gene promoters allowing the expression of tTA in transgenic mice containing the TRE-GFP-Tetanus Toxin transgene leading to the inhibition of neurotransmission in targeted neurons. Blockade of the direct pathway showed a decrease in cocaine-induced CPP whereas, in contrast to the studies reported above, no difference in CCP was found when the indirect pathway was inhibited (Hikida et al., 2010). These differences could be explained by the lower proportion (60-70\%) of neurons targeted by the two approaches. Altogether, by using different approaches, all based on conditional expression 
in MSN populations, these studies demonstrated that similar to their functions in motor control, striatopallidal, and striatonigral neurons display antagonistic roles in the control of reward behavior.

Optogenetic tools have also recently been used to investigate the involvement of NAc cholinergic interneurons in drug reinforcement. By conditional expression of ChR2 or the chloride pump halorhodopsin (eNpHR3.0) in choline acetyltransferase (ChAT)positive neurons, Witten and colleagues have demonstrated that the activation of cholinergic neurons by stimulation of ChR2 induced the decrease of MSN firing whereas their inhibition by stimulation of eNPHR3.0 induced an increase in MSNs firing in NAc (Witten et al., 2010). The inhibition of ChAT interneurons during cocaine exposure in the conditioning phase of a CPP paradigm induced a significant decrease in cocaine-induced CPP, demonstrating that striatal cholinergic interneurons control NAc MSN activity and consequently regulate cocaine-reward properties (Witten et al., 2010).

\section{EVALUATION OF THE DIFFERENTIAL ROLES OF STRIATOPALLIDAL AND STRIATONIGRAL NEURONS IN MOTOR AND REWARD BEHAVIORS BY CELL-TYPE SPECIFIC GENE OVEREXPRESSION OR INACTIVATION}

Thus, the recent development of these powerful techniques allowed to more precisely study the functional roles of striatopallidal and striatonigral neurons. Furthermore, the elucidation of these functional differences was also more and more addressed by using mice with cell-specific knock-out/knock-down of selected genes (i.e., ion channel, receptor) based on BAC-driven Cre recombinase expression or small hairpin RNA (ShRNA).

The first developed conditional striatonigral and striatopallidal models were the NSE-tTa 11A and 11B (tetracycline transactivator) mice which, when crossed with a transgenic line expressing a gene of interest driven by Tet-Op (tetracycline promoter), lead to the induction of this gene expression in the absence of doxycycline (Kelz et al., 1999; Werme et al., 2002). These models were particularly interesting because the gene expression can be induced at adulthood and then avoids developmental effect or gene compensation. Roles of $\Delta \mathrm{FosB}$, a transcription factor involved in response to drugs of abuse, have been studied in striatopallidal and striatonigral neurons using this strategy. Overexpression of $\Delta$ FosB in striatonigral neurons increased the reward and locomotor response to cocaine and morphine (Kelz et al., 1999; Zachariou et al., 2006) whereas overexpression in striatopallidal neurons did not affect the morphine reward properties (Zachariou et al., 2006), strongly supporting an instrumental role of $\Delta$ FosB in striatonigral neurons in reward properties of drugs.

Besides this first conditional model in the basal ganglia system, several groups also developed and used knock-in and BAC transgenic mice to express, under specific striatopallidal or striatonigral neuron promoters, either a protein of interest (Drago et al., 1998; Sano et al., 2003; Gantois et al., 2007), a mutant protein (Heusner and Palmiter, 2005), a shRNA (Novak et al., 2010) or the Cre recombinase used with conditional knock-out floxed mice (Heusner and Palmiter, 2005; Lemberger et al., 2007; Durieux et al., 2009).

The study of NMDA receptor roles in motor and reward functions in the striatum and more specifically in striatonigral neurons is a good example to demonstrate the usefulness of these different approaches. NMDA receptors are involved in the corticostriatal excitatory glutamatergic transmission on MSNs and play a central role in synaptic plasticity at these synapses (Calabresi et al., 1992). By using Drd1a- and Drd2-EGFP, Shen et al. (2008b) recently demonstrated the role of NMDA receptor in inducing long-term potentiation (LTP) either in striatopallidal or striatonigral neurons and its uselessness in the induction of long-term depression (LTD) in both populations. This could fit with several pharmacological studies showing the implication of striatal NMDA receptors in instrumental learning (Yin et al., 2005). By using a striatal-specific Cre mice (RGS9-Cre) and NMDAR1 (NR1) floxed mice, Dang et al. (2006) have demonstrated that deletion of NR1 subunit in the entire striatum led to a deficit in motor learning in a rotarod task associated with abolition of LTP in the dorsal striatum and LTD in the NAc. Agatsuma et al. (2010), showed more recently the involvement of striatal NR1 subunit in cocaine cue reactivity in a CPP paradigm. However, this model did not allow studying specific involvement of this receptor in the two MSN populations. To more specifically focus on striatonigral neurons, Heusner and Palmiter (2005) developed a knock-in model targeting expression of a NR1 subunit mutant driven by the $\mathrm{D}_{1}$ receptor promoter (Heusner and Palmiter, 2005) and, more recently, Beutler et al. (2011) crossed knock-in Drd1aCre mice with NR1 floxed mice. They demonstrated by these two independent approaches that altering NMDA signaling by either NR1 subunit deletion or NR1 mutant expression did not affect basal locomotor activity or acute locomotor response to psychostimulant (Heusner and Palmiter, 2005) but abolished the establishment of cocaine and amphetamine sensitization. Moreover, mice deleted in active NMDA receptors in striatonigral neurons are less sensitive to the rewarding effect of cocaine and amphetamine tested in a CPP paradigm compared to the wild-type littermates (Heusner and Palmiter, 2005; Beutler et al., 2011). Moreover, re-expression of NR1 only in striatonigral neurons by injection of AAV vector in the NAc of Drd1a-Cre mice restored amphetamine sensitization, therefore showing that the expression of NR1 in $\mathrm{D}_{1}$-expressing cells is sufficient to the development of AMPH sensitization (Beutler et al., 2011). In contrast, they also demonstrated that balanced loss of NMDA receptors in both MSN subtypes by using GPR88-Cre mice is permissive for the development of the sensitization. Therefore, removing the NMDA receptors and so compromising the glutamatergic activation in striatonigral neurons leads to an imbalance activity between the two MSN classes that probably promotes the inhibitory role of striatopallidal neurons on amphetamine sensitization. This indicates that an antagonistic balanced activity of striatopallidal and striatonigral neurons is also at works during the establishment of drug sensitization.

Besides ionotropic glutamate receptors, MSNs also highly express members of the group 1 metabotropic glutamate receptors (mGluR; Tallaksen-Greene et al., 1998). MSNs co-express mGluR1 and mGluR5 known to modulate their synaptic activity. mGluR1 and/or mGluR5 are involved in the potentiation of NMDA current, the suppression of GABAergic and glutamatergic transmissions via the activation of presynaptic CB1 receptors as well as in corticostriatal LTP and LTD (for review Bonsi et al., 2008). These forms of plasticity in striatal MSNs are proposed to be associated with motor learning but also associative learning and memory processes that might contribute to relapse like-behavior. The contribution 
of mGluR5 in these processes, either in striatonigral neurons or striatopallidal neurons, was investigated through the development of a mGluR5 knock-down mice (mGluR5 ${ }^{\mathrm{KD}-\mathrm{D} 1}$ ) expressing a small hairpin RNA targeting the mGluR5 under the control of $\mathrm{D}_{1}$ receptor promoter (Novak et al., 2010). By using a model of cue-induced reinstatement, Novak et al. (2010) showed that mGluR5 in striatonigral MSNs play a role in the reinstatement of cocaine behavior and is therefore required for specific incentive learning processes.

In addition to the central and interrelated roles of glutamatergic and dopaminergic transmissions, muscarinic acetylcholine receptors (Chmr) also tightly regulate the basal ganglia network. Disturbances in cholinergic transmission in this system have been suggested in pathologies as Parkinson's disease, depression, schizophrenia, and drug addiction (Felder et al., 2001; Langmead et al., 2008) and Chmr4 knock-out mice revealed their role in the modulation of the dopaminergic system activity through preand/or post-synaptic mechanisms (Gomeza et al., 1999; Tzavara et al., 2004).

Interestingly, Chmr4 are specifically co-expressed with dopamine $\mathrm{D}_{1}$ receptor in striatonigral neurons (Bernard et al., 1992; Ince et al., 1997). The physiological relevance of this specific cellular expression was recently analyzed by using the Cre/LoxP system to generate mice lacking Chmr4 specifically in $\mathrm{D}_{1}$ receptor-expressing striatonigral neurons ( $\mathrm{D}_{1}-\mathrm{M} 4-\mathrm{KO}$; Jeon et al., 2010). Phenotypical analyses of these $\mathrm{D}_{1}-\mathrm{M} 4-\mathrm{KO}$ mice revealed increase in their response to psychostimulants with increased hyperlocomotion to acute cocaine and amphetamine treatment and increased amphetamine-induced behavioral sensitization. This was accompanied by alterations in dopaminergic transmission, which could contribute to the hypersensitivity phenotype, both at the pre- and post-synaptic levels with an increased dopamine efflux in NAc and a lack of control of the $\mathrm{D}_{1}$-mediated signaling cascade in striatonigral neurons (Jeon et al., 2010), showing therefore the role of striatonigral MSN-expressed Chmr4 in the behavioral response to psychostimulants.

In contrast to striatonigral neurons, only few studies have been designed to examine and understand the roles of specific molecules in striatopallidal neurons in behavior. Nevertheless, the involvement of DARPP-32 and BNDF-Trkb signaling in both striatopallidal and striatonigral neurons has been investigated by conditional cell-specific deletion using Drd2-Cre and Drd1a-Cre mouse lines (Bateup et al., 2010; Lobo et al., 2010). Bateup and colleagues first demonstrated that DARPP-32 is essential for the induction for corticostriatal LTP both in striatopallidal and striatonigral neurons. Further, they showed that conditional deletion of DARPP-32 induces opposite behavioral alterations. Thus, the loss of DARPP-32 in striatopallidal neurons leads to an increased activity whereas this loss in striatonigral neurons results in decreased activity in basal and cocaine-induced locomotor activity. Cell-specific alterations of this signaling cascade highlighted that striatopallidal and striatonigral neurons exert an antagonistic control in mediating locomotor activity and behavioral effect of psychostimulants; striatonigral and striatopallidal neurons facilitating and inhibiting locomotion and rewarding effect of psychostimulants, respectively. Interestingly, only the loss of DARPP-32 in striatonigral neurons fully abolished L-DOPA-induced dyskinesia whilst its deletion in striatopallidal was without effect suggesting the important role of striatonigral DARPP-32 in the L-DOPA-induced dyskinesia. In addition and in the same line, Bateup et al. (2010) demonstrated that DARPP-32 deletion in striatopallidal neurons abolished the haloperidol-induced catalepsy.

BDNF-Trkb signaling has been implicated in the rewarding response to psychostimulants (Grimm et al., 2003; Graham et al., 2007, 2009; Schoenbaum et al., 2007) but the role of the striatopallidal and striatonigral neurons in this mechanism remains unclear. TrkB is expressed by both MSN subtypes but Trkb is significantly enriched in striatopallidal neurons (Lobo et al., 2010). Alteration BDNF-Trkb signaling induced molecular changes as showed by the surprising increase in c-fos expression in striatopallidal neurons and decrease in striatonigral neurons upon acute cocaine treatment while previous studies have demonstrated the selective increase of c-fos expression in striatonigral neurons (Bertran-Gonzalez et al., 2008). This alteration in c-fos expression is associated with a modification in MSN excitability. Striatopallidal neurons displayed a dramatic increase in neuronal firing in basal condition whereas striatonigral neurons displayed this increase only after cocaine treatment, probably due to $\mathrm{K}^{+}$ channel down-regulation. The increase in striatopallidal activity leads to the desensitization of the rewarding effect of cocaine whereas increase excitability of striatonigral neurons promotes the effect of cocaine (Lobo et al., 2010). Cell-specific deletion of Trkb confirmed the antagonistic role of striatopallidal and striatonigral neurons in the locomotor response to cocaine treatment, which is consistent with current models of basal ganglia circuit (Lobo et al., 2010).

As indicated above, Lobo et al. (2007) studied the new striatopallidal neuron-specific gene Gpr6 by using full knock-out mice highlighting its involvement in the control of the cAMP signaling cascade in these neurons and its role in instrumental learning. Involvement of adenosine $\mathrm{A}_{2 \mathrm{~A}}$ receptor, a well-known striatopallidal neuron-specific gene (Schiffmann and Vanderhaeghen, 1993; Schiffmann et al., 2007), has been extensively studied by using pharmacological tools and knock-out mice leading to apparent discrepant results. Contrary to the antagonist $\mathrm{A}_{2 \mathrm{~A}}-\mathrm{D}_{2}$ interaction model in the striatum (Ferre et al., 1997), based on various data including electrophysiological studies showing antagonistic $\mathrm{A}_{2 \mathrm{~A}}-\mathrm{D}_{2}$ control of $\mathrm{D}_{2}$-GFP MSN membrane potential oscillations through $\mathrm{A}_{2 \mathrm{~A}}-\mathrm{D}_{2}$ receptors heteromerization (Azdad et al., 2009b) and pharmacological studies (Filip et al., 2006), global genetic deletion (Chen et al., 2000, 2003; Soria et al., 2006) or more specific deletion in the forebrain (using CamKII $\alpha$-Cre mouse line and floxed $\mathrm{A}_{2 \mathrm{~A}}$ receptor mice; Bastia et al., 2005) led to an attenuation rather than a increase of the locomotor effect induced by psychostimulants. Reconciling these different results, deletion of $A_{2 \mathrm{~A}}$ receptor specifically at the post-synaptic level in striatal neurons by using Dlx5-6-Cre mice showed that, in contrast to forebrain deletion, acute administration of cocaine resulted in an enhanced cocaine-induced locomotor activity (Shen et al., 2008a), that could be explained by the antagonistic interaction between $\mathrm{A}_{2 \mathrm{~A}} \mathrm{R}$ and $\mathrm{D}_{2} \mathrm{R}$ in striatopallidal neurons. These results showing opposite effects of pre- and post-synaptic $\mathrm{A}_{2 \mathrm{~A}} \mathrm{R}$ nicely illustrate the importance of having adequate tools to inactivate genes in specific neuronal populations to decipher their functions. In addition, using devaluation omission behavioral assay for habit formation, Yu et al. (2009) demonstrated that $\mathrm{A}_{2 \mathrm{~A}} \mathrm{R}$ deletion in striatopallidal 
Table 1 | Behavioral phenotype in striatopallidal neuron-specific transgenic mouse models.

\begin{tabular}{|c|c|}
\hline Specific neuronal inhibition or ablation model & Specific neuronal activation model (optogenetic tools) \\
\hline Increased basal locomotor activity (Durieux et al., 2009) & Decreased basal locomotor activity and increased freezing (Kravitz et al., 2010) \\
\hline Increased rewarding effect of amphetamine (Durieux et al., 2009) & Decreased rewarding effect of cocaine (Lobo et al., 2010) \\
\hline \multicolumn{2}{|l|}{ Increased amphetamine sensitization (Ferguson et al 2010) } \\
\hline \multicolumn{2}{|l|}{ SPECIFIC GENETARGETING } \\
\hline $\begin{array}{l}\text { Increased basal locomotor activity in DARPP-32 conditional } \\
\text { knock-out mice (Bateup et al., 2010) }\end{array}$ & Habit formation alteration in striatopallidal neuron- $A_{2 A} R$ knock-out (Yu et al., 2009) \\
\hline $\begin{array}{l}\text { Increased acute cocaine-induced hyperlocomotion in DARPP-32 } \\
\text { conditional knock-out mice (Bateup et al., 2010) }\end{array}$ & Instrumental conditioning affected by GPR6 deletion (Lobo et al., 2007) \\
\hline $\begin{array}{l}\text { Decreased rewarding effect of cocaine in TrkB conditional } \\
\text { knock-out mice (Lobo et al., 2010) }\end{array}$ & Disruption of haloperidol-induced catalepsy (Bateup et al., 2010) \\
\hline
\end{tabular}

Table 2 | Behavioral phenotype in striatonigral neuron-specific transgenic mouse models.

Specific neuronal inhibition model (optogenetic tools)

Decreased amphetamine sensitization (Ferguson et al., 2010)

Increased rewarding effect of cocaine (Lobo et al., 2010)

\section{SPECIFIC GENETARGETING}

Decreased basal locomotor activity, acute cocaine-induced hyperlocomotion

and I-DOPA-induced dyskinesia in DARPP-32 conditional

knock-out mice (Bateup et al., 2010)

Increased locomotor response and rewarding effect of cocaine and

morphine by $\Delta$ FosB overexpression (Zachariou et al.,2006)

Increased rewarding effect of cocaine in TrkB conditional

knock-out mice (Lobo et al.,2010)
Specific neuronal activation model (optogenetic tools)

Increased basal locomotor activity and

decreased freezing (Kravitz et al., 2010)

\author{
Alteration of cue-induced reinstatement in striatonigral \\ neuron mGluR5 knock-down mice (Novak et al., 2010) \\ Increased cocaine and amphetamine acute \\ hyperlocomotion and behavioral sensitization \\ in D1-M4-KO (Jeon et al., 2010) \\ Abolished sensitization and decreased rewarding effect of \\ psychostimulant in striatonigral neuron NR1 \\ subunit-lacking mice (Beutler et al., 2011)
}

neurons led to a selective deficit in instrumental learning and hence revealed the importance of $A_{2 A} R$-mediated signaling cascade in striatopallidal neurons for habit formation.

\section{CONCLUSION}

Data summarized in this review extraordinarily extend our understanding of signaling pathways and mechanisms that are selectively activated in striatopallidal and striatonigral neurons in response to different stimuli, demonstrating the differential implication of these neuron sub-populations in the control of motor and druginduced behaviors (see Tables 1 and 2). This rapid extension was render possible by the critical development of new technologies in the last decade allowing to specifically identify and study these two key neuronal populations in the striatum.

First, specific identification of striatopallidal and striatonigral neurons has given the opportunity to investigate more precisely molecular pathways involved in different conditions, i.e., in psychostimulant responses. Furthermore, genome wide analysis of striatal

\section{REFERENCES}

Agatsuma, S., Dang, M. T., Li, Y., and Hiroi, N. (2010). N-methyl-D-aspartic acid receptors on striatal neurons are essential for cocaine cue reactivity in mice. Biol. Psychiatry 67, 778-780.
Albin, R. L., Young, A. B., and Penney, J. B. (1989). The functional anatomy of basal ganglia disorders. Trends Neurosci. 12, 366-375.

Azdad, K., Chavez, M., Don Bischop, P., Wetzelaer, P., Marescau, B., De Deyn,

MSNs provided a huge number of new genes and molecular pathways that are specifically present in striatopallidal and striatonigral neurons. The functional relevance of these genes and pathways represent an important challenge that will be analyzed in the future. Finally, the development of cell-specific models using Cre lines and conditional floxed mice is profoundly changing the way we analyze basal ganglia functions and allows to much better investigate striatopallidal and striatonigral neuron properties and to dissect molecular mechanisms underlying their differential functions in the basal ganglia circuit.

\section{ACKNOWLEDGMENTS}

Sabrina Ena was supported by a FRIA fellowship from the FRSFNRS (Belgium) and a Biowin grant from the Walloon Region (Hope4PD); AdKdE is Research Associate of the FRS-FNRS (Belgium). The studies of the authors were supported by FMRE (Belgium), FRS-FNRS (Belgium), FER from ULB, Action de Recherche Concertée from the CFWB.

P. P., Gall, D., and Schiffmann, S. N. (2009a). Homeostatic plasticity of striatal neurons intrinsic excitability following dopamine depletion. PLoS ONE 4, e6908. doi: 10.1371/journal. pone. 0006908
Azdad, K., Gall, D., Woods, A. S., Ledent, C., Ferre, S., and Schiffmann, S. N. (2009b). Dopamine D2 and adenosine $\mathrm{A} 2 \mathrm{~A}$ receptors regulate NMDA-mediated excitation in accumbens neurons through 
A2A-D2 receptor heteromerization. Neuropsychopharmacology 34, 972-986.

Bastia, E., Xu, Y. H., Scibelli, A. C., Day, Y. J., Linden, J., Chen, J. F., and Schwarzschild, M.A. (2005).A crucial role for forebrain adenosine $\mathrm{A}(2 \mathrm{~A})$ receptors in amphetamine sensitization. Neuropsychopharmacology 30, 891-900.

Bateup, H. S., Santini, E., Shen, W., Birnbaum, S., Valjent, E., Surmeier, D. J., Fisone, G., Nestler, E. J., and Greengard, P. (2010). Distinct subclasses of medium spiny neurons differentially regulate striatal motor behaviors. Proc. Natl. Acad. Sci. U.S.A. 107, 14845-14850.

Bateup, H. S., Svenningsson, P., Kuroiwa, M., Gong, S., Nishi, A., Heintz, N., and Greengard, P. (2008). Cell typespecific regulation of DARPP-32 phosphorylation by psychostimulant and antipsychotic drugs. Nat. Neurosci. 11, 932-939.

Belin, D., Jonkman, S., Dickinson, A., Robbins, T. W., and Everitt, B. J. (2009). Parallel and interactive learning processes within the basal ganglia: relevance for the understanding of addiction. Behav. Brain Res. 199, 89-102.

Bernard, V., Normand, E., and Bloch, B. (1992). Phenotypical characterization of the rat striatal neurons expressing muscarinic receptor genes. J. Neurosci. 12, 3591-3600.

Bertran-Gonzalez, J., Bosch, C., Maroteaux, M., Matamales, M., Herve, D., Valjent, E., and Girault, J. A. (2008). Opposing patterns of signaling activation in dopamine D1 and D2 receptorexpressing striatal neurons in response to cocaine and haloperidol. J. Neurosci. 28, 5671-5685.

Bertran-Gonzalez, J., Hakansson, K., Borgkvist, A., Irinopoulou, T., BramiCherrier, K., Usiello, A., Greengard, P., Herve, D., Girault, J.A., Valjent, E., and Fisone, G. (2009). Histone H3 phosphorylation is under the opposite tonic control of dopamine D2 and adenosine A2A receptors in striatopallidal neurons. Neuropsychopharmacology 34, 1710-1720.

Beutler, L. R., Wanat, M. J., Quintana, A., Sanz, E., Bamford, N. S., Zweifel, L. S., and Palmiter, R. D. (2011). Balanced NMDA receptor activity in dopamine D1 receptor (D1R)- and D2Rexpressing medium spiny neurons is required for amphetamine sensitization. Proc. Natl. Acad. Sci. U.S.A. 108, 4206-4211.

Bolam, J. P., Hanley, J. J., Booth, P. A., and Bevan, M. D. (2000). Synaptic organisation of the basal ganglia. J. Anat. 196 (Pt 4), 527-542.

Bonsi, P., Platania, P., Martella, G., Madeo, G., Vita, D., Tassone, A., Bernardi, G., and Pisani, A. (2008). Distinct roles of group I mGlu receptors in striatal function. Neuropharmacology 55, 392-395.

Borgkvist, A., Valjent, E., Santini, E., Herve, D., Girault, J. A., and Fisone, G. (2008). Delayed, context- and dopamine D1 receptor-dependent activation of ERK in morphine-sensitized mice. Neuropharmacology 55, 230-237.

Buch, T., Heppner, F. L., Tertilt, C., Heinen, T. J., Kremer, M., Wunderlich, F. T., Jung, S., and Waisman, A. (2005). A Cre-inducible diphtheria toxin receptor mediates cell lineage ablation after toxin administration. Nat. Methods 2, 419-426.

Calabresi, P., Pisani,A., Mercuri, N. B., and Bernardi, G. (1992). Long-term potentiation in the striatum is unmasked by removing the voltage-dependent magnesium block of NMDA receptor channels. Eur. J. Neurosci. 4, 929-935.

Chao, J., and Nestler,E. J. (2004). Molecular neurobiology of drug addiction. Annu. Rev. Med. 55, 113-132.

Chen, J. F., Beilstein, M., Xu, Y. H., Turner, T. J., Moratalla, R., Standaert, D. G., Aloyo, V. J., Fink, J. S., and Schwarzschild, M. A. (2000). Selective attenuation of psychostimulantinduced behavioral responses in mice lacking $\mathrm{A}(2 \mathrm{~A})$ adenosine receptors. Neuroscience 97, 195-204.

Chen, J. F., Moratalla, R., Yu, L., Martin, A. B., Xu, K., Bastia, E., Hackett, E., Alberti, I., and Schwarzschild, M. A. (2003). Inactivation of adenosine A2A receptors selectively attenuates amphetamine-inducedbehavioral sensitization. Neuropsychopharmacology 28, 1086-1095.

Comings, D. E. (2001). Clinical and molecular genetics of ADHD and Tourette syndrome. Two related polygenic disorders. Ann. N. Y. Acad. Sci. 931, 50-83.

Dang, M. T., Yokoi, F., Yin, H. H., Lovinger, D. M., Wang, Y., and Li, Y. (2006). Disrupted motor learning and longterm synaptic plasticity in mice lacking NMDAR1 in the striatum. Proc. Natl. Acad. Sci. U.S.A. 103, 15254-15259.

Day, M., Wang, Z., Ding, J., An, X., Ingham, C.A., Shering, A. F., Wokosin, D., Ilijic, E., Sun, Z., Sampson, A. R., Mugnaini, E., Deutch, A. Y., Sesack, S. R., Arbuthnott, G. W., and Surmeier, D. J. (2006). Selective elimination of glutamatergic synapses on striatopallidal neurons in Parkinson disease models. Nat. Neurosci. 9, 251-259.

Delong, M. R. (1990). Primate models of movement disorders of basal ganglia origin. Trends Neurosci. 13, 281-285.

Delong, M. R., and Wichmann, T. (2007). Circuits and circuit disorders of the basal ganglia. Arch. Neurol. 64, 20-24.
Drago, J., Padungchaichot, P., Wong, J. Y., Lawrence, A. J., Mcmanus, J. F., Sumarsono, S. H., Natoli, A. L., Lakso, M., Wreford, N., Westphal, H., Kola, I., and Finkelstein, D. I. (1998). Targeted expression of a toxin gene to D1 dopamine receptor neurons by cremediated site-specific recombination. J. Neurosci. 18, 9845-9857.

Durieux, P. F., Bearzatto, B., Guiducci, S., Buch, T., Waisman, A., Zoli, M., Schiffmann, S. N., and de Kerchove d'Exaerde, A. (2009). D2R striatopallidal neurons inhibit both locomotor and drug reward processes. Nat. Neurosci. 12, 393-395.

Farde, L., Wiesel, F. A., Halldin, C., and Sedvall, G. (1988). Central D2-dopamine receptor occupancy in schizophrenic patients treated with antipsychotic drugs. Arch. Gen. Psychiatry 45, 71-76.

Felder, C. C., Porter, A. C., Skillman, T. L., Zhang, L., Bymaster, F. P., Nathanson, N. M., Hamilton, S. E., Gomeza, J., Wess, J., and Mckinzie, D. L. (2001) Elucidating the role of muscarinic receptors in psychosis. Life Sci. 68, 2605-2613.

Ferguson, S. M., Eskenazi, D., Ishikawa, M., Wanat, M. J., Phillips, P. E., Dong, Y., Roth, B. L., and Neumaier, J. F. (2010). Transient neuronal inhibition reveals opposing roles of indirect and direct pathways in sensitization. Nat. Neurosci. 14, 22-24.

Ferre, S., Fredholm, B. B., Morelli, M., Popoli, P., and Fuxe, K. (1997). Adenosine-dopamine receptorreceptor interactions as an integrative mechanism in the basal ganglia. Trends Neurosci. 20, 482-487.

Filip, M., Frankowska, M., Zaniewska, M., Przegalinski, E., Muller, C. E., Agnati, L., Franco, R., Roberts, D. C., and Fuxe, K. (2006). Involvement of adenosine $\mathrm{A} 2 \mathrm{~A}$ and dopamine receptors in the locomotor and sensitizing effects of cocaine. Brain Res. 1077, 67-80.

Fisone, G., Hakansson, K., Borgkvist, A., and Santini, E. (2007). Signaling in the basal ganglia: postsynaptic and presynaptic mechanisms. Physiol. Behav. 92, 8-14.

Gantois, I., Fang, K., Jiang, L., Babovic, D., Lawrence, A. J., Ferreri, V., Teper, Y., Jupp, B., Ziebell, J., MorgantiKossmann, C. M., O’brien, T. J., Nally, R., Schutz, G., Waddington, J., Egan, G. F., and Drago, J. (2007). Ablation of D1 dopamine receptor-expressing cells generates mice with seizures, dystonia, hyperactivity, and impaired oral behavior. Proc. Natl. Acad. Sci. U.S.A. 104, 4182-4187.

Gerfen, C. R., Engber, T. M., Mahan, L. C., Susel, Z., Chase, T. N., Monsma, F. J. Jr., and Sibley, D. R. (1990). D1 and D2 dopamine receptor-regulated gene expression of striatonigral and striatopallidal neurons. Science 250, 1429-1432.

Gerfen, C. R., and Young, W. S. III. (1988). Distribution of striatonigral and striatopallidal peptidergic neurons in both patch and matrix compartments: an in situ hybridization histochemistry and fluorescent retrograde tracing study. Brain Res. 460, 161-167.

Gertler, T. S., Chan, C. S., and Surmeier, D. J. (2008). Dichotomous anatomical properties of adult striatal medium spiny neurons. J. Neurosci. 28, 10814-10824.

Girault, J. A., Valjent, E., Caboche, J., and Herve, D. (2007). ERK2: a logical AND gate critical for drug-induced plasticity? Curr. Opin. Pharmacol. 7, 77-85.

Gomeza, J., Zhang, L., Kostenis, E., Felder, C., Bymaster, F., Brodkin, J., Shannon, H., Xia, B., Deng, C., and Wess, J. (1999). Enhancement of D1 dopamine receptor-mediated locomotor stimulation in $\mathrm{M}(4)$ muscarinic acetylcholine receptor knockout mice. Proc. Natl. Acad. Sci. U.S.A. 96, 10483-10488.

Gong, S., Doughty, M., Harbaugh, C. R., Cummins, A., Hatten, M. E., Heintz, N., and Gerfen, C. R. (2007). Targeting Cre recombinase to specific neuron populations with bacterial artificial chromosome constructs. J. Neurosci. 27, 9817-9823.

Gong, S., Zheng, C., Doughty, M. L., Losos, K., Didkovsky, N., Schambra, U. B., Nowak, N. J., Joyner, A., Leblanc, G. Hatten, M. E., and Heintz, N. (2003). A gene expression atlas of the central nervous system based on bacterial artificial chromosomes. Nature 425, 917-925.

Graham, D. L., Edwards, S., Bachtell, R. K., Dileone, R. J., Rios, M., and Self, D. W. (2007). Dynamic BDNF activity in nucleus accumbens with cocaine use increases self-administration and relapse. Nat. Neurosci. 10, 1029-1037.

Graham, D. L., Krishnan, V., Larson, E. B., Graham, A., Edwards, S., Bachtell, R. K., Simmons, D., Gent, L. M., Berton, O., Bolanos, C. A., Dileone, R. J., Parada, L. F., Nestler, E. J., and Self, D. W. (2009). Tropomyosin-related kinase B in the mesolimbic dopamine system: region-specific effects on cocaine reward. Biol. Psychiatry 65, 696-701.

Graybiel, A. M. (2000). The basal ganglia. Curr. Biol. 10, R509-R511.

Graybiel, A. M. (2005). The basal ganglia: learning new tricks and loving it. Curr. Opin. Neurobiol. 15, 638-644.

Graybiel, A. M., Aosaki, T., Flaherty, A. W., and Kimura, M. (1994). The basal ganglia and adaptive motor control. Science 265, 1826-1831.

Grimm, J. W., Lu, L., Hayashi, T., Hope, B. T., Su, T. P., and Shaham, Y. (2003). 
Time-dependent increases in brainderived neurotrophic factor protein levels within the mesolimbic dopamine system after withdrawal from cocaine: implications for incubation of cocaine craving. J. Neurosci. 23, 742-747.

Heiman, M., Schaefer, A., Gong, S., Peterson, J. D., Day, M., Ramsey, K. E., Suarez-Farinas, M., Schwarz, C., Stephan, D. A., Surmeier, D. J., Greengard, P., and Heintz, N. (2008). A translational profiling approach for the molecular characterization of CNS cell types. Cell 135, 738-748.

Heusner, C. L., and Palmiter, R. D. (2005). Expression of mutant NMDA receptors in dopamine D1 receptorcontaining cells prevents cocaine sensitization and decreases cocaine preference.J. Neurosci. 25, 6651-6657.

Hikida, T., Kimura, K., Wada, N., Funabiki, K., and Nakanishi, S. (2010). Distinct roles of synaptic transmission in direct and indirect striatal pathways to reward and aversive behavior. Neuron 66, 896-907.

Hikosaka, O., Takikawa, Y., and Kawagoe, R. (2000). Role of the basal ganglia in the control of purposive saccadic eye movements. Physiol. Rev. 80, 953-978.

Ince, E., Ciliax, B. J., and Levey, A. I. (1997). Differential expression of D1 and D2 dopamine and $\mathrm{m} 4$ muscarinic acetylcholine receptor proteins in identified striatonigral neurons. Synapse $27,357-366$.

Jeon, J., Dencker, D., Wortwein, G., Woldbye, D. P., Cui, Y., Davis, A. A., Levey, A. I., Schutz, G., Sager, T. N., Mork, A., Li, C., Deng, C. X., FinkJensen, A., and Wess, J. (2010). A subpopulation of neuronal M4 muscarinic acetylcholine receptors plays a critical role in modulating dopaminedependent behaviors. J. Neurosci. 30, 2396-2405.

Kawaguchi, Y., Wilson, C. J., Augood, S. J., and Emson, P. C. (1995). Striatal interneurons: chemical, physiological, and morphological characterization. Trends Neurosci. 18, 527-535.

Kelz, M. B., Chen, J., Carlezon, W. A. Jr., Whisler, K., Gilden, L., Beckmann, A. M., Steffen, C., Zhang, Y. J., Marotti, L., Self, D. W., Tkatch, T., Baranauskas, G., Surmeier, D. J., Neve, R. L., Duman, R. S., Picciotto, M. R., and Nestler, E. J. (1999). Expression of the transcription factor deltaFosB in the brain controls sensitivity to cocaine. Nature 401, 272-276.

Keshavan, M. S., Tandon, R., Boutros, N. N., and Nasrallah, H. A. (2008). Schizophrenia, "just the facts": what we know in 2008 part 3: neurobiology. Schizophr. Res. 106, 89-107.

Kravitz, A. V., Freeze, B. S., Parker, P. R., Kay, K., Thwin, M. T., Deisseroth, K., and Kreitzer, A. C. (2010). Regulation of parkinsonian motor behaviours by optogenetic control of basal ganglia circuitry. Nature 466, 622-626.

Langmead, C. J., Watson, J., and Reavill, C. (2008). Muscarinic acetylcholine receptors as CNS drug targets. Pharmacol. Ther. 117, 232-243.

Le Moine, C., Normand, E., and Bloch, B. (1991). Phenotypical characterization of the rat striatal neurons expressing the D1 dopamine receptor gene. Proc. Natl. Acad. Sci. U.S.A. 88, 4205-4209.

Lee, K. W., Kim, Y., Kim, A. M., Helmin, K., Nairn, A. C., and Greengard, P. (2006). Cocaine-induced dendritic spine formation in D1 and D2 dopamine receptor-containing medium spiny neurons in nucleus accumbens. Proc. Natl.Acad. Sci. U.S.A. 103, 3399-3404.

Lemberger, T., Parlato, R., Dassesse, D., Westphal, M., Casanova, E., Turiault, M., Tronche, F., Schiffmann, S. N., and Schutz, G. (2007). Expression of Cre recombinase in dopaminoceptive neurons. BMC Neurosci. 8, 4 .

Levesque, M., Bedard, A., Cossette, M., and Parent,A. (2003). Novel aspects of the chemical anatomy of the striatum and its efferents projections. J. Chem. Neuroanat. 26, 271-281.

Lobo, M. K., Covington, H. E. III., Chaudhury, D., Friedman, A. K., Sun, H., Damez-Werno, D., Dietz, D. M., Zaman, S., Koo, J. W., Kennedy, P. J., Mouzon, E., Mogri, M., Neve, R. L., Deisseroth, K., Han, M. H., and Nestler, E. J. (2010). Cell type-specific loss of BDNF signaling mimics optogenetic control of cocaine reward. Science 330, 385-390.

Lobo, M. K., Cui, Y., Ostlund, S. B., Balleine, B.W., and Yang, X. W. (2007). Genetic control of instrumental conditioning by striatopallidal neuronspecific S1P receptor Gpr6. Nat. Neurosci. 10, 1395-1397.

Lobo, M. K., Karsten, S. L., Gray, M., Geschwind, D. H., and Yang, X. W. (2006). FACS-array profiling of striatal projection neuron subtypes in juvenile and adult mouse brains. Nat. Neurosci. 9, 443-452.

Lobo, M. K., Yeh, C., and Yang, X. W. (2008). Pivotal role of early B-cell factor 1 in development of striatonigral medium spiny neurons in the matrix compartment. J. Neurosci. Res. 86, 2134-2146.

Matamales, M., Bertran-Gonzalez, J., Salomon, L., Degos, B., Deniau, J. M., Valjent, E., Herve, D., and Girault, J.A. (2009). Striatal medium-sized spiny neurons: identification by nuclear staining and study of neuronal subpopulations in BAC transgenic mice. PLoS ONE 4, e4770. doi: 10.1371/ journal.pone.0004770
Meurers, B. H., Dziewczapolski, G., Shi, T., Bittner, A., Kamme, F., and Shults, C. W. (2009). Dopamine depletion induces distinct compensatory gene expression changes in DARPP-32 signal transduction cascades of striatonigral and striatopallidal neurons. J. Neurosci. 29, 6828-6839.

Nicola, S. M. (2007). The nucleus accumbens as part of a basal ganglia action selection circuit. Psychopharmacology (Berl.) 191, 521-550.

Novak, M., Halbout, B., O'connor, E. C., Rodriguez Parkitna, J., Su, T., Chai, M., Crombag, H. S., Bilbao, A., Spanagel, R., Stephens, D. N., Schutz, G., and Engblom, D. (2010). Incentive learning underlying cocaine-seeking requires mGluR5 receptors located on dopamine D1 receptor-expressing neurons. J. Neurosci. 30, 11973-11982.

Packard, M. G., and Knowlton, B. J. (2002). Learning and memory functions of the basal ganglia. Annu. Rev. Neurosci. 25, 563-593.

Saka, E., and Graybiel, A. M. (2003) Pathophysiology of Tourette's syndrome: striatal pathways revisited. Brain Dev. 25(Suppl. 1), S15-S19.

Sano, H., Yasoshima, Y., Matsushita, N., Kaneko, T., Kohno, K., Pastan, I., and Kobayashi, K. (2003). Conditional ablation of striatal neuronal types containing dopamine D2 receptor disturbs coordination of basal ganglia function. J. Neurosci. 23, 9078-9088.

Santini, E., Alcacer, C., Cacciatore, S. Heiman, M., Herve, D., Greengard, P., Girault, J. A., Valjent, E., and Fisone, G. (2009). L-DOPA activates ERK signaling and phosphorylates histone $\mathrm{H} 3$ in the striatonigral medium spiny neurons of hemiparkinsonian mice. J. Neurochem. 108, 621-633.

Schiffmann, S. N., Fisone, G., Moresco, R., Cunha, R. A., and Ferre, S. (2007). Adenosine A2A receptors and basal ganglia physiology. Prog. Neurobiol. 83, 277-292.

Schiffmann, S. N., Jacobs, O., and Vanderhaeghen, J. J. (1991). Striatal restricted adenosine A2 receptor (RDC8) is expressed by enkephalin but not by substance P neurons: an in situ hybridization histochemistry study. J. Neurochem. 57, 1062-1067.

Schiffmann, S. N., and Vanderhaeghen, J. J. (1993). Adenosine A2 receptors regulate the gene expression of striatopallidal and striatonigral neurons. J. Neurosci. 13, 1080-1087.

Schoenbaum, G., Stalnaker, T. A., and Shaham, Y. (2007). A role for BDNF in cocaine reward and relapse. Nat. Neurosci. 10, 935-936.

Shalizi, A., Gaudilliere, B., Yuan, Z., Stegmuller, J., Shirogane, T., Ge, Q., Tan, Y., Schulman, B., Harper, J. W. and Bonni, A. (2006). A calcium- regulated MEF2 sumoylation switch controls postsynaptic differentiation. Science 311, 1012-1017.

Shen, H. Y., Coelho, J. E., Ohtsuka, N., Canas, P. M., Day, Y. J., Huang, Q. Y., Rebola, N., Yu, L., Boison, D., Cunha, R. A., Linden, J., Tsien, J.Z., and Chen, J.F. (2008a). A critical role of the adenosine A2A receptor in extrastriatal neurons in modulating psychomotor activity as revealed by opposite phenotypes of striatum and forebrain A2A receptor knock-outs. J Neurosci.

Shen, W., Flajolet, M., Greengard, P., and Surmeier, D. J. (2008b). Dichotomous dopaminergic control of striatal synaptic plasticity. Science 321, 848-851.

Shepherd, J. D., Rumbaugh, G., Wu, J., Chowdhury, S., Plath, N., Kuhl, D., Huganir, R. L., and Worley, P. F. (2006). Arc/Arg3.1 mediates homeostatic synaptic scaling of AMPA receptors. Neuron 52, 475-484.

Shiflett, M.W., and Balleine, B.W. (2010). Contributions of ERK signaling in the striatum to instrumental learning and performance. Behav. Brain Res. 218, 240-247.

Shuen, J. A., Chen, M., Gloss, B., and Calakos, N. (2008). Drdla-tdTomato BAC transgenic mice for simultaneous visualization of medium spiny neurons in the direct and indirect pathways of the basal ganglia. J. Neurosci. 28, 2681-2685.

Soria, G., Castane, A., Ledent, C., Parmentier, M., Maldonado, R., and Valverde, O. (2006). The lack of $\mathrm{A} 2 \mathrm{~A}$ adenosine receptors diminishes the reinforcing efficacy of cocaine. Neuropsychopharmacology 31 , 978-987.

Steward, O., and Worley, P.F. (2001). A cellular mechanism for targeting newly synthesized mRNAs to synaptic sites on dendrites. Proc. Natl. Acad. Sci. U.S.A. 98, 7062-7068.

Stipanovich, A., Valjent, E., Matamales, M., Nishi, A., Ahn, J. H., Maroteaux M., Bertran-Gonzalez, J., BramiCherrier, K., Enslen, H., Corbille, A. G., Filhol, O., Nairn, A. C., Greengard, P., Herve, D., and Girault, J. A. (2008). A phosphatase cascade by which rewarding stimuli control nucleosomal response. Nature 453, 879-884.

Tallaksen-Greene, S. J., Kaatz, K. W., Romano, C., and Albin, R. L. (1998). Localization of mGluR1a-like immunoreactivity and mGluR5-like immunoreactivity in identified populations of striatal neurons. Brain Res. 780, 210-217.

Tepper, J. M., and Bolam, J. P. (2004). Functional diversity and specificity of neostriatal interneurons. Curr. Opin. Neurobiol. 14, 685-692.

Tian, X., Kai, L., Hockberger, P. E., Wokosin, D. L., and Surmeier, D. J. 
(2010). MEF-2 regulates activitydependent spine loss in striatopallidal medium spiny neurons. Mol. Cell. Neurosci. 44, 94-108.

Tzavara, E. T., Bymaster, F. P., Davis, R. J., Wade, M. R., Perry, K. W., Wess, J., Mckinzie, D. L., Felder, C., and Nomikos, G. G. (2004). M4 muscarinic receptors regulate the dynamics of cholinergic and dopaminergic neurotransmission: relevance to the pathophysiology and treatment of related CNS pathologies. FASEB J. 18, 1410-1412.

Valjent, E., Corvol, J. C., Trzaskos, J. M., Girault, J. A., and Herve, D. (2006). Role of the ERK pathway in psychostimulant-induced locomotor sensitization. BMC Neurosci. 7, 20. doi: 10.1186/1471-2202-7-20

Valjent, E., Pascoli, V., Svenningsson, P., Paul, S., Enslen, H., Corvol, J. C., Stipanovich, A., Caboche,
J., Lombroso, P. J., Nairn, A. C., Greengard, P., Herve, D., and Girault, J. A. (2005). Regulation of a protein phosphatase cascade allows convergent dopamine and glutamate signals to activate ERK in the striatum. Proc. Natl. Acad. Sci. U.S.A. 102, 491-496.

Walaas, S.I., Aswad, D. W., and Greengard, P. (1983). A dopamine- and cyclic AMP-regulated phosphoprotein enriched in dopamine-innervated brain regions. Nature 301, 69-71.

Werme, M., Messer, C., Olson, L., Gilden, L., Thoren, P., Nestler, E. J., and Brene, S. (2002). Delta FosB regulates wheel running. J. Neurosci. 22, 8133-8138.

Witten, I. B., Lin, S. C., Brodsky, M., Prakash, R., Diester, I., Anikeeva, P., Gradinaru, V., Ramakrishnan, C., and Deisseroth, K. (2010). Cholinergic interneurons control local circuit activity and cocaine conditioning. Science 330, 1677-1681.
Yin, H. H., and Knowlton, B. J. (2006) The role of the basal ganglia in habit formation. Nat. Rev. Neurosci. 7, 464-476.

Yin, H. H., Knowlton, B. J., and Balleine, B. W. (2005). Blockade of NMDA receptors in the dorsomedial striatum prevents action-outcome learning in instrumental conditioning. Eur. J. Neurosci. 22, 505-512.

Yu, C., Gupta, J., Chen, J. F., and Yin, H. H. (2009). Genetic deletion of A2A adenosine receptors in the striatum selectively impairs habit formation. $J$. Neurosci. 29, 15100-15103.

Zachariou, V., Bolanos, C. A., Selley, D. E., Theobald, D., Cassidy, M. P., Kelz, M. B., Shaw-Lutchman, T., Berton, O., Sim-Selley, L. J., Dileone, R. J., Kumar, A., and Nestler, E. J. (2006). An essential role for DeltaFosB in the nucleus accumbens in morphine action. Nat. Neurosci. 9, 205-211.
Conflict of Interest Statement: The authors declare that the research was conducted in the absence of any commercial or financial relationships that could be construed as a potential conflict of interest.

Received:29June 2011; paperpending published: 17 July 2011; accepted: 18 July 2011; published online: 28 July 2011.

Citation: EnaS, de Kerchove d'Exaerde A and Schiffmann SN (2011) Unraveling the differential functions and regulation of striatal neuronsub-populations in motor control, reward, and motivational processes. Front. Behav. Neurosci. 5:47.doi: 10.3389/fnbeh.2011.00047 Copyright (c) 2011 Ena, de Kerchove d'Exaerde and Schiffmann. This is an open-access article subject to an exclusive license agreement between the authors and Frontiers Media SA, which permits unrestricted use, distribution, and reproduction in any medium, provided the original authors and source are credited. 